\begin{tabular}{|c|c|}
\hline & $\begin{array}{l}\text { International Journal of Trend in Scientific } \\
\text { Research and Development (IJTSRD) }\end{array}$ \\
\hline 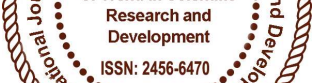 & International Open Access Journal \\
\hline 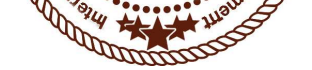 & ISSN No: 2456 - 6470 | www.ijtsrd.com | Volume - 2 | Issue - 2 \\
\hline
\end{tabular}

\title{
Biodiesel from Jatropha curcas -A truth of our future
}

\author{
Vinay kumar Gupta \\ Research Scholar, Chemical Engineering Department, \\ Monad University, \\ Hapur, India
}

\author{
Jai Singh \\ Chemical Engineering Department, \\ C.C.S. University, \\ Meerut, India
}

\begin{abstract}
The raising industrialization and advancement of the world has to a vertical hoisted for the request of oil based fuel. Monetary advancement in creating nations has prompted cyclopean increment in the vitality require. To satisfy our prerequisite for utilization of vitality, we should utilize biodiesel in light of the fact that Petroleum has restricting stock in world. Jatropha is utilized for a long time as an imperative premise of fuel yet it isn't acclaimed like biodiesel from soya oil and palm oil. The yield of jatropha is considerably higher than some other biodiesel crops and it has some extraordinary property than some other crops. The Jatropha plant has natural reclamation and it has ability to develop in the got dried out condition where the other biodiesel crops discover hard to survive. So Jatropha is best option for production of biodiesel.
\end{abstract}

Keywords: Jatropha, SVO, FFA (Free fatty acid), Transesterification, biodiesel etc.

\section{INTRODUCTION:}

In 1912 Diesel stated: "The utilization of vegetable oils for motor powers may appear to be irrelevant today. In future such oils may progress and will become as important as oil and the coal tar results of the present time." Those days the cost of diesel petrol is lower and it has advantaged accessibility. Accordingly petrol and diesel completely dismissed vegetable oil in 1920. In perspective of that, diesel motors were more reasonable to work with petroldiesel because of lower viscosity [1]. In close to the starting 1980, because of deficiency of oil supply, vitality security and to influence contamination to free nature, it is important to move elective wellsprings of vitality like biodiesel. People groups were restarted business creation of biodiesel in 1990. Since vegetable oils have elevated viscosity and minor volatility, so it has denied atomization and coking inclination to the injectors and ignition chamber in adapted diesel motor. To determine these inconveniences, a few unsuccessful techniques including smaller scale emulsification and weakening were found. In addition, some proficient cures, for example, pyrolysis, supercritical methanol, and transesterification were additionally analyzed to diminish the higher viscosity of regular oils. The last approach has been appeared to be most encouraging to overcome the high viscosity issue by changing the regular oils into their alkyl esters called "biodiesel". Biodiesel can be utilized as a part of existing diesel motors with little or no alterations inferable from its comparative physical properties to those of mineral diesel. Other than inexhaustibility, ecological supportability worries because of over the top utilization of petroleum derivatives have likewise featured the surge of enthusiasm for biodiesel. Dissimilar to petro-diesel, biodiesel is biodegradable and nontoxic and can considerably diminish the measure of fumes outflows, especially unburned hydrocarbon, particulates materials, and carbon monoxide [2]. 
In any case, as a general rule biodiesel can be portrayed as a twofold edged sword with both positive and negative effects. Biodiesel advocates assert that it can possibly be "carbon- impartial" over its life cycle and can prompt a cleaner ignition [2]. Moreover, some natural gatherings express that biodiesel could bring about huge deforestation. For the most part, biodiesel can be created from an assortment of accommodate stocks including (1) creature fats, for example, yellow lubricate fat, (2) unique vegetable oils, for example, palm, soybean, and rapeseed oils; and (3) non-consumable oils, for example, karanja, jatropha, castor oil, neem oil, green growth, and so forth.; and (4) squander vegetable oil[1]. At the present express, the primary classification can just supplant oil diesel worldwide utilization by a little level of up to around 3\% if the greater part of the delivered nourishment review oils are transesterified[3]. Then again, it is lucky that the energy of the biodiesel business in non-palatable oils creation as supportable biodiesel accommodate stock. Moreover, it ought to be notable that broad planting of non-consumable oils could bring about abundance of treatment, arrive utilize change and pesticide utilize. In the meantime as, creation of non-eatable vegetable oils in peripheral grounds can just cover an inconsequential division of the general diesel fuel required.

It is justify that albeit a standout amongst the most critical capable powers at the back the improvement of biodiesel is to seek after a diminishment in reliance on non-renewable energy sources, the greater part of the stages associated with the creation of its feedstock and amalgamation are tied up with utilization of petroleum derivatives. Then again, lesser vitality substance of biodiesel, enormous amount of glycerol delivered, high water usage amid the downstream procedures, and poor icy properties could be specified as the fundamental disservices of biodiesel general utilization. In this manner, these appearances ought to be vanquishing by future endeavors to help the naturally generous parts of biodiesel. Jatropha oil is additionally a sort of vegetable oil that is delivered from the seeds of jatropha that can develop in immaterial and typical terrains.

\section{JATROPHA PLANT AS A REPLACEMENT OF FUEL:}

Jatropha curcas is a dearth-resistant recurrent, growing well in trivial/poor soil. It is easy to establish, grows comparatively rapidly and lives, generating seeds for 50 years. Jatropha the surprise plant produces seeds with oil contented of $37 \%$. The oil can be combusted as fuel without being refined. It has been tried effectively as fuel for straightforward diesel motor subsequent it consumes with clear sans smoke fire. It is observed to develop in numerous parts of the nation, rough in nature and can get by with least sources of info and simple to transmit [4]. Jatropha curcas is turning into the future wellspring of biodiesel for world. The arranging commission diverse nation has started a decided program of developing Jatropha curcas on misuse arrive for biodiesel creation. Among the distinctive oil seeds, Jatropha curcas has been discovered more appropriate for biodiesel generation based on various highlights. The cultivating of Jatropha is conceivable under consistent stress circumstance and the oil of these species having different highlights is extra suitable for biodiesel creation. Jatropha curcas has been experimentally created to give enhanced efficiency and yield of oil. Jatropha oil has higher cetane no. (51) contrasted with different oils and contrast with diesel (46-50) and make it a perfect elective fuel and requires no transformation in the motor. An examination has been done on biodiesel from Jatropha oil as a vehicle fuel for some nations and found that this will spare remote trade and lessen $\mathrm{CO}_{2}$ outflow [5].

\subsection{BENEFITS OF FARMING OF JATROPHA CURCAS:}

I. It is a speedy yielding animal varieties even in ominous land conditions, as debased and fruitless grounds under timberland and non-woodland utilize, dry and dry spell inclined region, minimal terrains even an antacid soils and furthermore as agro ranger service crops.

II. Jatropha can be developed in dry zone $(20 \mathrm{~cm}$ rainfall) and additionally in higher rainfall districts and even ashore with their dirt cover.

III. Jatropha can be a decent plant material for ecoreclamation in a wide range of leave. It develops rapidly and sets up itself effortlessly.

IV. Jatropha develops promptly from plant cuttings or seeds up to one side of 3-5 m. Jatropha are not viewed as great rummage material. No relocation of sustenance crops is basic [6]. 
V. The plant is exceedingly vermin and illness rebellious. It normally repulses creepy crawlies and creatures don't look through it.

VI. It kills carbon from the air gather and aides in the development of soil carbon.

VII. It is dry season rebellious.

VIII. It adjusts well to minor soils with low supplement content.

IX. It is moderately simple to spread.

$\mathrm{X}$. It isn't obtrusive or harming.

XI. It is equipped for settling sand ridges, going about as a windbreak or fighting desertification.

XII. It lives for more than 50 years delivering seeds constantly.

XIII. It is strong against the chilly and It doesn't require costly yield pivot

XIV. It doesn't deplete the supplements in the land; rather, it restores abused land.

$\mathrm{XV}$. It doesn't require manures and it has a high productivity.

The biodiesel by product, glycerin, is profitable in itself. The waste plant mass after oil extraction can be used as a fertilizer. The plant itself recycles $100 \%$ of the $\mathrm{Co}_{2}$ emissions produced by burning the biodiesel; two mature plants can absorb 1 metric ton of carbon every year [7].

\subsection{BIODIESEL AND ITS NEED OF LAND IN WORLD}

Minor rural land is assessed for biodiesel generation in Africa, China, Europe, India, South America, and the mainland United States, which have major agrarian creation limits. These nations/locales can have 320-702 million hectares of land accessible if just relinquished and corrupted cropland and blended product and vegetation arrive, which are for the most part of low quality, are accounted [8]. In the event that prairie of savanna, and scrubland with peripheral yield are estimated for planting low-input high-decent variety (LIHD) blends of tenant perennials as vitality crops, the aggregate land accessibility can increment from 1107-1411 million hectares, in the event that the brushing land is shoddy. Planting the second age gathering of biodiesel tank on relinquished and corrupted cropland and low-input high-decent variety (LIHD) intermittent on prairie with unimportant profitability may finish $26-55 \%$ of the present world fluid fuel utilization, without influencing the utilization of land with customary efficiency for traditional crops and without influencing the present brushing land. Under the different land utilize circumstances, Africa may have more than $33 \%$, and Africa and Brazil, together, may have the greater part of the aggregate land accessible for biodiesel creation. These conclusions depend on physical circumstances, for example, soil efficiency, ground incline and atmosphere [8].

\subsection{Jatropha Plantation's Yield:}

Jatropha plant stands organic products from second year of its estate and the financial yield stabilizers from fourth or fifth year onwards. The plant has a normal existence with viable yield up to 50 years. Jatropha gives around $2 \mathrm{~kg}$ of seed for every plant in generally poor soils [4]. The yields of seed have been accounted for as $0.75-1.00 \mathrm{~kg}$ for each plant in this way the money related yield can be considered to run in the vicinity of 0.75 and $2.00 \mathrm{~kg} / \mathrm{plant}$ and 4.00 and 6.00 MT for every hectare every year relying upon agro-climatic zone and farming practices [5]. One hectare of estate all things considered soil will give 1.6 MT oil as appeared in Table 1[9]. The cost of farming home has been assessed as Rs. 20,000/ - per hectare complete of plant material, upkeep for 1 year, preparing use, and so forth., incorporates components, for example, site arrangement, planting administration, composts, water system, deseeding and plant insurance seed gathering, seed handling, etc[10].

Table 1: Productivity of Jatropha plantation

\begin{tabular}{|l|l|l|}
\hline Sr.No & Quantity / hectare & Productivity \\
\hline 1 & Seeds/hectare (MT) & $4-6$ \\
\hline 2 & Oil/hectare (MT) & $1.5-2$ \\
\hline 3 & Biodiesel/hectare (MT) & $1.35-1.38$ \\
\hline 4 & $\begin{array}{l}\text { Cost of plantation/hectare } \\
\text { (Rs.) }\end{array}$ & 20,000 \\
\hline
\end{tabular}




\section{METHODS FOR MODIFICATION OF STRAIGHT VEGETABLE OIL (SVO) IN TO BIODIESEL}

In perspective of the issue of direct utilization of SVO and regular occasional updating of motor, it is beneficial to utilize adjustment techniques that assistance to diminish the viscosity of oil/give the item reasonable as fuel. Numerous standardized methodologies are accessible for the adjustment of SVO, for example, blending, Micro-emulsification, Cracking and transesterification to decrease its viscosity. Transesterification response is utilized to creation of biodiesel. Transesterification is the most widely recognized strategy for changing over oil into biodiesel that can be utilized straightforwardly or as
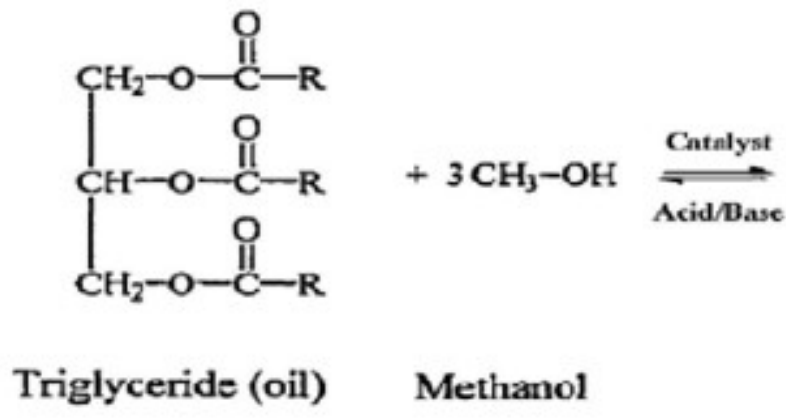

mixes with diesel in diesel motor. It is additionally called alcoholysis, is uprooting of liquor from an ester by liquor in a procedure like hydrolysis, with the exception of that a liquor is utilized rather than water. This procedure has been generally used to decrease the viscosity of triglycerides $[11,12]$. A transesterification response is spoken to in Fig. 1. Essential, corrosive or enzymatic in nature, an impetus is generally used to accelerate the response. The whole transesterification can be spoken to by three stages. Transesterification is a strategy for changing of an ester into another when a vegetable oil is responded with methanol and the protest of impetus to give methyl ester (biodiesel) and measure of glycerine.

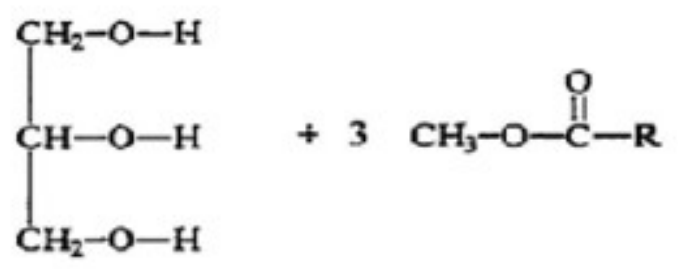

\section{Glycerol Mixture of methyl ester:}

Fig 1: Transesterification reaction

The transesterification procedure will happen in the reactor and once the biodiesel has been made, it will be gone through a progression of procedures to isolate is from the results and remaining reactants. Figure 1 demonstrates the procedure for the creation of biodiesel by means of the transesterification procedure. This figure demonstrates the reactants being put into a cluster reactor where the transesterification response happens. The item from the reactor is taken through a progression of divisions units. These detachments steps isolate the biodiesel from the results and remaining reactants.

\subsection{FACTORS AFFECTING THE TRANSESTERIFICATION REACTIONS}

The most important variables that influence the transesterification reaction are:

I. REACTION TEMPERATURE: Temperature plainly controls the response and generation of the biodiesel. A higher response temperature can diminish the viscosities of oils and result in an expanded response rate, and an abbreviated response time. In any case, Leung and Guo and Eevera et al. discovered that when the response temperature increments past the ideal level, the yield of the biodiesel item diminishes in light of the fact that a higher response temperature accelerates the saponification response of triglycerides. The response temperature must be a little sum than the breaking point of liquor with a specific end goal to guarantee that the liquor won't spill out through vaporization [13]. Contingent upon the oil utilized, the ideal temperature ranges from $50^{\circ} \mathrm{C}$ to $60^{\circ} \mathrm{C}$.

II. RATIO OF ALCOHOL TO VEGETABLE OIL: Numerous analysts know about that one of the fundamental components impacting the yield of biodiesel is the molar proportion of liquor to triglyceride. Hypothetically it has been demonstrated that the proportion for transesterification response requires $3 \mathrm{~mol}$ of liquor for $1 \mathrm{~mol}$ of triglyceride to create $3 \mathrm{~mol}$ of unsaturated fat ester and $1 \mathrm{~mol}$ of glycerol. An excess of liquor is utilized as a part of biodiesel produce to ensure that the oils or fats will be totally changed to esters and a higher liquor triglyceride proportion can bring about a more prominent ester transformation in a shorter time [13]. The yield of 
biodiesel is expanded when the liquor triglyceride proportion is lifted past 3 and achieves a most extreme. Additional expanding the liquor amount more distant than the greatest proportion won't build the yield however will build cost for liquor recuperation. What's more, the molar proportion is related with the sort of impetus utilized and the molar proportion of liquor to triglycerides in many examinations is $6: 1$, with the utilization of a salt impetus. At the point when the level of free unsaturated fats in the oils or fats is high, for example, on account of waste cooking oil, a molar proportion as high as $15: 1$ is required when utilizing corrosive catalyzed transesterification.

\section{CATALYST CONCENTRATION:}

Impetus fixation can influence the yield of the biodiesel item. As specified previously, the most regularly utilized impetus for the response is sodium hydroxide. In any case, Freedman et al. discovered that sodium methoxide was more compelling than sodium hydroxide in light of the fact that after blending sodium hydroxide with methanol a little measure of water will be created, which will influence the item yield in light of the hydrolysis response. This is the motivation behind why the impetus ought to be included into the methanol first and then blended with the oil. As the impetus focus builds the transformation of triglyceride and the yield of biodiesel increment. This is on the grounds that a deficient measure of impetuses results in an inadequate change of the triglycerides into the unsaturated fat esters. Normally, the yield achieves an ideal esteem when the impetus $(\mathrm{NaOH})$ focus achieves 1.5 wt. \% and then reductions a little with a further increment in impetus fixation. The lessening of the yield of the biodiesel is because of the expansion of unreasonable antacid impetus making more triglycerides respond with the salt impetus and shape more cleanser.

\subsection{TYPES OF TRANSESTERIFICATION}

3.2.1: ACID CATALYZED TRANSESTERIFICATION: When the measure of FFA substance in the oil is over $1 \%$, corrosive is utilized to catalyze the transesterification response. This is known as corrosive catalyzed esterification response, used to lessen FFA substance and increment the yield of alkyl esters.

\subsection{2: BASE CATALYZED}

TRANSESTERIFICATION: When base is utilized to catalyze the transesterification response, it is known as base Catalyst transesterification response. It is utilized when the measure of FFA substance are under $1 \%$. In this progression, change of triglycerides into alkyl ester and glycerol happen. The lighter layer (biodiesel) is isolated from heavier glycerol stage by partition. The lighter biodiesel is evacuated, washed with water, dried over anhydrous sodium sulfate and can be utilized straightforwardly as motor fuel in diesel motors.

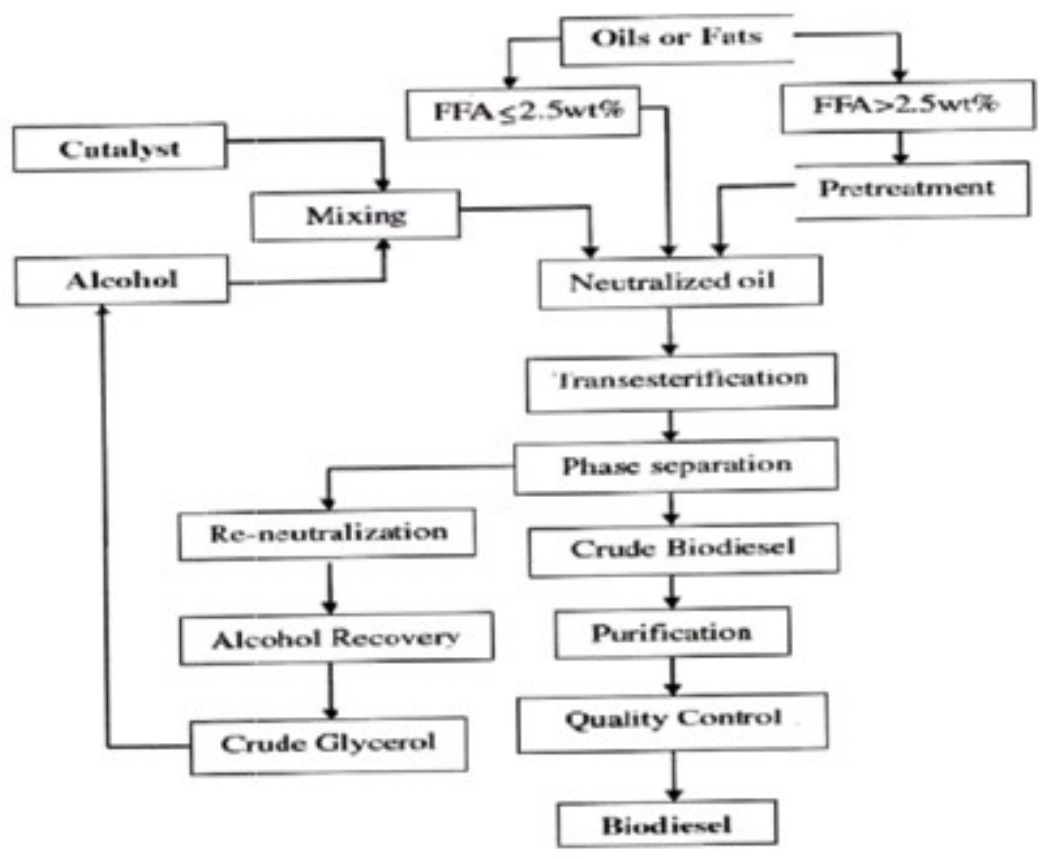


Fig: 2. Simplified process flow chart of alkali-catalyzed biodiesel production

4. COMPARISON OF EMISSIONS FROM BIODIESEL AND DIESEL: The writing has revealed that the motor activity on biodiesel blended with diesel gave bring down outflow than diesel fuel expect if there should be an occurrence of NOX. It is watched that in the event of NOX, there is increment in $2 \%$ NOX with B20 utilize and 10\% with B100 utilize. The arrangement of emanation of biodiesel and diesel is given in Table 2. Biodiesel utilize is lower than diesel aside from NOX. The higher of NOX outflow could be lessened either by slight retard of infusion timing (1- 5 degree) or by utilization of exhaust system. The life cycle examination of biodiesel demonstrates that the decrease in $\mathrm{CO}_{2}$ outflow is around $16 \%$ with $\mathrm{B} 20$ and $72 \%$ with $\mathrm{B} 100$ use on per liter burning premise $[9,14]$.

Table 2: Emission comparisons of biodiesel and diesel

\begin{tabular}{|l|l|l|l|}
\hline Sr.No. & Emission type & B100 & B20 \\
\hline 1 & Hydrocarbon (HC) & $-67 \%$ & $-20 \%$ \\
\hline 2 & $\mathrm{CO}$ & $-48 \%$ & $-12 \%$ \\
\hline 3 & $\begin{array}{l}\text { Particulate matter } \\
\text { (PM) }\end{array}$ & $-47 \%$ & $-2 \%$ \\
\hline 4 & $\mathrm{NOx}$ & $+10 \%$ & $+2 \%$ \\
\hline 5 & $\mathrm{SO} 2$ & $-100 \%$ & $-20 \%$ \\
\hline 6 & $\mathrm{PAH}$ & $-80 \%$ & $-13 \%$ \\
\hline
\end{tabular}

low instability, marginally higher viscosity and higher

4. PERFORMANCE OF DIESEL ENGINE WITH BIODIESEL AND ITS BLENDS WITH DIESEL

Biodiesel demonstrated palatably execution amid diesel motor task. The utilization of B20 in diesel motor gives relatively same mileage as with diesel fuel. Because of high greased up in nature, it gives less wear and tear in motor development. Numerous examinations on the exhibitions and emanation of pressure start motors, fuelled with unadulterated biodiesel and mixes with diesel oil have been performed and are accounted for in the writing.

The BTE for biodiesel for all mixes run (B10 to B100) was discovered relatively tantamount to that of diesel. Maybe because of prevalent cetane number and intrinsic nearness of oxygen in the biodiesel delivered better ignition. Furthermore the Jatropha and its mixes have bring down viscosity. The decrease in viscosity of Jatropha prompts enhanced atomization, fuel vaporization and ignition. The start hold-up time is likewise near diesel. The BTE for B10 (22.08), B20 (22) and B30 (21.03) was found about almost get a kick out of the chance to diesel (23.39) individually. The low proficiency might be because of thickness of the biodiesel of Jatropha oil, and likewise because of quality of higher unsaturation in Jatropha biodiesel which influences blend development of the fuel and in this way coordinates to moderate burning.

The nearness of oxygen in the biodiesel prompts more entire burning, bringing about lower emanation in NOX discharge has been estimated because of higher temperature. An examination has managed in AHEC, IIT Roorkee with the creation of biodiesel from Jatropha oil and introduction assessment of 2 kilo Volt Ampere Diesel generator set on mixes of biodiesel and diesel at different burdens. The brake warm productivity is discovered higher up to B30 in contrast with diesel while BTE of B100 (24\%) was nearly equivalents to diesel $(24.5 \%)$ for JOME. While the brake particular fuel utilization for B100 was $14.8 \%$ higher than diesel for biodiesel from Jatropha oil at full load, in this way showing the utilization of $100 \%$ biodiesel can create same yield of vitality utilizing higher measure of biodiesel and consequently it should turn into the "On Farmer Fuel" where rancher can develop his own particular asset, change over to biodiesel and use in horticultural sets itself without the need of any diesel for blending [13]. 


\section{CONCLUSION:}

The present investigation has managed the examination the possibility of biodiesel from Jatropha in world. The generation of biodiesel per hectare for Jatropha is more prominent than four times contrasted with fuel per hectare as soybean oil and is more noteworthy up to ten times of corn oil. The brake warm proficiency is discovered higher up to B30 in contrast with diesel while BTE of B100 (24\%) was nearly equivalents to diesel (24.5\%) for JOME. The investigations recommend that biodiesel can altogether substitute diesel for IC motor, despite the fact that higher measure of B100 fuel should be used and no motor issue was experienced over the span of experimentations. In this exploration Jatropha curcas plant is turning into the prospect establishment of biodiesel for world. Much nation has begun a decided program of delivering Jatropha curcas on squander land to create biodiesel. Jatropha curcas has been discovered more fitting for biodiesel generation based on an assortment of highlights among the different oil seeds. The creating of biodiesel from Jatropha Curcas seeds has been partitioned into two noteworthy stages one is extraction of seed oil and other one is Conversion of seed oil to biodiesel. The transesterification procedure is the most efficacious and practicable approach to fabricate the biodiesel utilizing the Jatropha seed oil. Jatropha curcas has been demonstrated deductively to give better yield and profitability of oil. Downsides of Jatropha biodiesel oil has higher cetane no. and higher viscosity contrasted with diesel .So it makes thick fuel and requires somewhat alteration in the cutting edge IC motor. Fundamental trouble with biodiesel is that it oxidized while in connect with condition as for time which extra prompt increment in fuel viscosity. Research is going ahead at national and additionally global level for controlling the oxidation of biodiesel from eatable seeds. Be that as it may, much exertion is required around there for biodiesel from nonconsumable seeds moreover.

\section{REFERENCES}

1. Hosseinpour, Soleiman, et al. "Exact estimation of biodiesel cetane number $(\mathrm{CN})$ from its fatty acid methyl esters (FAMEs) profile using partial least square (PLS) adapted by artificial neural network (ANN)." Energy Conversion and Management 124 (2016): 389-398.
2. Aghbashlo, Mortaza, and Ayhan Demirbas. "Biodiesel: hopes and dreads." Biofuel Research Journal 3.2 (2016): 379-379.

3. Pahl, Greg. Biodiesel: growing a new energy economy. Chelsea Green Publishing, 2008.

4. Jain, Siddharth, and M. P. Sharma. "Prospects of biodiesel from Jatropha in India: a review." Renewable and Sustainable Energy Reviews 14.2 (2010): 763-771.

5. Palit, Debajit, Ramit Malhotra, and Sanjay Mande. "Enhancing viability of biofuel-based decentralized power projects for rural electrification in India." Environment, Development and Sustainability: 1-21.

6. Biswas, S., N. Kaushik, and G. Srikanth. "Biodiesel: technology and business opportunities-an insight." Proceedings of the biodiesel Q conference toward energy independance-Focus of Jatropha, Hyderabad, India. 2006.

7. Darzins, Al, Philip Pienkos, and Les Edye. "Current status and potential for algal biofuels production." A report to IEA Bioenergy Task 39 (2010).

8. Cai, Ximing, Xiao Zhang, and Dingbao Wang "Land availability for biofuel production." Environmental science \& technology 45.1 (2010): 334-339.

9. "Shrivastava, Nitin, S. N. Varma, and Mukesh Pandey. "An experimental investigation of performance and exhaust emission of a diesel engine fuelled with Jatropha biodiesel and its blends." International Journal of Energy and Environment 3.6 (2012): 915-926.

10. Yadav, Amit Kumar, and Vijai Krishna. "Sustainable energy production from Jatropha biodiesel." International Journal of Advancements in Research \& Technology 1.5 (2012): 1-6.

11. Barnwal BK, Sharma MP. Prospects of biodiesel production from vegetable oils in India. Renewable and Sustainable Energy Reviews 2005;9:363-78.

12. Sharma MP, Agarwal R. Non-edible oils as potential resources of biodiesel. In: Proceedings of the 23rd National Convention of Chemical Engineers on recent trends in chemical engineering; 2007. p. 202-11. 
International Journal of Trend in Scientific Research and Development (IJTSRD) ISSN: 2456-6470

13. Uma Krishnakumar, V. Sivasubramanian (2016)

Optimization of Lab-Scale Preparation of Biodiesel from Rubber Seed Oil Using Modified

Calcium Oxide as Catalyst. Journal of Sustainable Bioenergy Systems, 06, 55-65. doi: 10.4236/jsbs.2016.63006

14. Labeckas G, Salvinskos Stasys M. The effect of rape seed oil methyl ester on direct injection diesel engine performance and exhaust emission. Energy Conversion and Management 2005. 